\title{
Gender \& Health: Towards a Consensus on Rights, Policy and Public Opinion
}

Social scientists have long held that gender differs from biological sex indicated by an 'M' or 'F' written on a birth certificate, since it encompasses constructs and roles assigned by different societies to each sex. The nature of gender and its effects on opportunities and outcomes in every social arena-health included-have fuelled academic and political debates and been the subject of four major UN conferences.

Gender has been recognized as a primary determinant of health practically from the minute the phrase was coined, but the 2012 World Development Report: Gender Equality and Development describes uneven progress over the past 25 years in women's status and opportunities, both geographically and by indicator. It cites, for example, persisting gender wage gaps but an acceleration in global narrowing of the gender education gap, with some regions, countries or subpopulations lagging behind. At the same time, disparities are emerging that disadvantage men and boys, such as higher secondary school dropout and repetition rates.

Adding sexual orientation and gender diversity to this picture demands further definitions, more profound analysis and respect for rights long negated. Addressing gender-related issues in any field thus requires nothing short of taking on social transformation.

Cuba and its health sector are certainly not exempt from the tensions and negative outcomes that gender inequities, machismo and patriarchal dominance produce. However, the gains made to date provide substantial foundation for further progress: access for women to higher education, reproductive rights and services, professional advancement, and relative economic independence. And more recently, we have seen forward movement in defending the rights of homosexual and transsexual persons.

To set the stage for this complex and challenging issue, we interviewed Mariela Castro, director of Cuba's National Sex Education Center, institutional champion of gender equity and sexual diversity (Revolutionizing Gender). Her analysis emerges from a rights-based approach to gender, and takes off to treat some of the most sensitive questions about gender in Cuban society and health today, including the unfinished agenda of women's rights, homo- and transphobia, controversial bills before parliament, and domestic violence.

In a related article, Roque and Rodríguez offer a clear and evidencebased defense of the need for a cultural shift on transsexuality and nonhegemonic gender relations, and of policies and legislation to further protect the health and rights of transsexual persons. (The Right to Health Care for Transsexual People in Cuba).

Artiles assesses application of a gender perspective in the Cuban health system's policy development, program design, implementation and evaluation, with the ultimate goal of gender equity. She also raises some tough questions (Incorporating a Gender Perspective into Cuba's Health System: Realities and Challenges).

Journalist Dixie Trinquete spices up this issue with her Viewpoint on Cuban television and its potential to challenge and change the public's mind (High Time: Cuban TV Serials Spur Debate on Sensitive Social Issues).

\section{Addressing gender-related issues in any field requires nothing short of taking on social transformation} risk women from earlier generations-suggesting that health care providers take these differences to heart to improve communication and care (Speaking from Experience: Today's Cuban Women and Breast Cancer).

Three articles treat very different populations of Cuban women: Navarro's research findings caution that calendar age should not by itself be the reason women and their physicians write off late childbearing (Hormone Profile of Menopausal Women in Havana). Carvajal examines the secrets of the world's most winning women's volleyball team-the Cubans who took gold in three successive Olympic Games (Kinanthropometric Profile of Cuban Women Olympic Volleyball Champions). And finally, Santiesteban makes an initial foray into research on the burdens of (mainly women) caregivers of children with HIVIAIDS (Mental Health of Primary Caregivers for Children and Adolescents with HIVIAIDS in Cuba).

On other topics, this issue of MEDICC Review also presents the first research in Cuba and internationally using electrophysiological techniques to study reorganization of tactile cortical areas as an effect of cross-modal plasticity. Charoó's study provides encouraging evidence for neuroplasticity in children with profound deafness and low vision (Cross-Modal Plasticity in Cuban Visually-Impaired Child Cochlear Implant Candidates: Topography of Somatosensory Evoked Potentials).

Finally, we are pleased to reprint Guzmán's important article reviewing the history of Cuba's public health response to the 1981 dengue hemorrhagic fever epidemic, a piece that is bound to become a classic from this distinguished researcher at Cuba's Tropical Medicine Institute, a WHO/PAHO Collaborating Center for the Study and Control of Dengue (Thirty Years after the Cuban Hemorrhagic Dengue Epidemic of 1981).

We invite you to submit your letters reflecting on this issue's articles, introducing your own views and experience regarding the polemical theme of gender and health, thus enriching the debate on this complex and critical question.

We wish to express our gratitude to the Ford Foundation and The Atlantic Philanthropies for their financial support for this issue. $-1 /$ -

\section{The Editors}

